\title{
Intracellular targeting and functional analysis of single-chain Fv fragments in mammalian cells
}

\author{
Alessio Cardinale, Ilaria Filesi, Sonia Mattei, and Silvia Biocca* \\ Department of Neuroscience, University of Roma “Tor Vergata," Via Montpellier, 1, 00133 Rome, Italy
}

Accepted 8 April 2004

Available online 7 July 2004

\begin{abstract}
In the past decade, intracellular antibodies have proven to be a useful tool in obtaining the phenotypic knock-out of selected gene function in different animal and plant systems. This strategy is based on the ectopic expression of recombinant forms of antibodies targeted towards different intracellular compartments, exploiting specific targeting signals to confer the new intracellular location. The functional basis of this technology is closely linked to the ability of intracellular antibodies to interact with their target antigens in vivo. This interaction allows either a direct neutralising effect or the dislodgement of the target protein from its normal intracellular location and, by this mechanism, the inactivation of its function. By using this approach, the function of several antigens has been inhibited in the cytoplasm, the nucleus, and the secretory compartments. In this article, we shall describe all the steps required for expressing single-chain Fv fragments in different subcellular compartments of mammalian cells and their subsequent use in knockout experiments, starting from a cloned single-chain Fv fragment. This will include the analysis of the solubility properties of the new $\mathrm{scFv}$ fragment in transfected mammalian cells, the intracellular distribution of the antigen-antibody complex, and the resulting phenotype.
\end{abstract}

(c) 2004 Elsevier Inc. All rights reserved.

Keywords: Intracellular antibody; scFv fragment; Targeting signal; Green fluorescent protein; Fluorescence microscopy; Aggresome; Proteasome

\section{Introduction}

Intracellular antibodies are a relatively new technology based on the concept that antibody chains or domains, if equipped with suitable localisation signals, can be targeted towards new ectopic intracellular sites to interfere with endogenous antigens [1-4]. This can be obtained by exploiting the property of dominant and autonomous targeting sequences that can be grafted onto other reporter proteins such as antibodies to confer them a new intracellular localisation. Recombinant antibody domains, in particular single-chain $\mathrm{Fv}(\mathrm{scFv})^{1}$ fragments, have been successfully expressed inside cells to inhibit the function of several antigens in the cytoplasm [5,6], the nucleus [7,8], and the secretory pathway of mammalian cells [9]. This type of strategy has a great potential for a variety of applications, including gene therapy [10], plant biotechnology [11] and, more recently, functional genomics $[4,12,26]$.

Crucial to the efficacy of this approach is the capacity of the intracellular antibody to interact with the endogenous antigen within any compartment of a mammalian cell. This interaction may result in a direct inhibition of the target antigen $[6,13,14]$, may restore a mutant deficient activity [15] or may interfere with the protein folding of pathological mutant proteins [16]. In a different mode of action, an intracellular antibody can also act by diverting

\footnotetext{
${ }^{*}$ Corresponding author. Fax: +39-6-72596407.

E-mail address: biocca@med.uniroma2.it (S. Biocca).

${ }^{1}$ Abbreviations used: scFv, single-chain variable fragment; VH and VL, variable domains of the heavy (H) and light (L) chains of an immunoglobulin; ER, endoplasmic reticulum; PDGF, platelet-derived growth factor; NLS, nuclear localisation sequence; GFP, green fluorescent protein; DTT, dithiothreitol; PMSF, phenylmethanesulfonyl fluoride; FITC, fluorescein isothiocyanate-conjugated; PVDF, poly(vinylidene difluoride); ECL, enhanced chemiluminescence; CD, chromodomain; HP1 $\beta$, heterochromatin protein $1 \beta$; BrdU, bromodeoxyuridine; UPS, ubiquitin-proteasome system; $\beta \mathrm{Gal}, \beta$ galactosidase; NGF, nerve growth factor; scPs, single-chain proteasome substrate.
} 
the intracellular traffic of the antigen. This is the case, for example, of membrane receptors, whose appearance at the surface can be inhibited by the interaction with intracellular antibodies retained in the endoplasmic reticulum by retention signals (intracellular anchors) [17,18].

As it was clear from the very beginning of work on this technology, the folding properties of the antibodies and antibody domains vary according to individual $\mathrm{scFv}$ fragments and to the intracellular compartment where they are located. A systematic comparison of scFvs targeted to the same compartment showed that antibody fragments expressed from identical expression vectors have very distinct properties of solubility and stability $[19,20]$. Although some scFvs are soluble in the cell cytoplasm, overexpression of these molecules may lead to the formation of intracellular aggregates. For this reason, there is great interest in engineering frameworks suitable for intracellular expression and onto which other specificities could be grafted. Different approaches have been developed to solve this problem, including modification of the sequence of $\mathrm{VH}$ and $\mathrm{VL}$ domains utilising random mutations to stabilise scFvs with intrinsic stability [21] or, alternatively, genetic selection approaches to derive functional scFvs, which can tolerate the reducing cellular environments of the cell cytoplasm [22-24].

Notwithstanding the phenomenon of aggregation, cytosolic $\mathrm{scFv}$ fragments maintain the capacity to bind the antigen and, by sequestering it in intracellular aggregates, to divert it from its intracellular location and block its function. A number of examples indicate that the antibody-mediated co-aggregation of the antigen represents a mode of action for intracellular antibodies targeted to the cytoplasm and to the nucleus [25-28].

The purpose of this paper was to discuss certain aspects of the intracellular antibody technology that are worth considering in order to start a project with this powerful approach. In addition, we shall describe methods for the analysis of: (i) the expressed $\mathrm{scFv}$ fragments, (ii) in vivo interaction with the endogenous antigen, and (iii) the assessment of the resulting biological activity. Since, during the past decade, we have focussed our studies on the expression of scFv fragments in the cytoplasm and in the nucleus of mammalian cells, we shall provide examples and protocols for the analysis of antibody domains in these compartments. Reagents and methodological considerations related to each issue are described below in the context of our work on p21Ras and heterochromatin proteins 1 (HP1).

\section{Description of methods}

\subsection{Intracellular targeting of scFvs}

Starting from a cloned scFv fragment, a set of general vectors have been described for the expression of these fragments in different cellular compartments of mammalian cells [29]. All the plasmids contain an N- or C-terminal localisation signal that allows the correct retargeting of the scFv fragment. Table 1 shows the amino-acid sequences of some of the sorting peptides that have been successfully used so far for targeting antibodies or antibody domains (in particular scFv fragments) to different intracellular compartments.

To target scFvs towards the secretory pathway of non-lymphoid mammalian cells, immunoglobulin leader sequences have so far proven to be very efficient. To retain soluble antibodies in the endoplasmic reticulum (ER), the ER-retaining sequence SEKDEL can be added at the C-terminus of the antibody [19]. Antibodies retained in the ER can therefore be used as intracellular anchors to prevent the appearance of a protein on the plasma membrane, or to inhibit the secretion of a protein. Whether this will occur will depend on whether the antigen is processed in the ER in a form recognised by the antibody, and this should be verified for each case.

$\mathrm{ScFv}$ fragments have been targeted to the plasma membrane, by incorporating the transmembrane and cytoplasmic domains of the T cell receptor $\zeta$ chain [30] and the PDGF-receptor transmembrane domain [31].

The complete removal of the leader (leaderless), leaving the $\mathrm{N}$-terminal methionine, leads to the localisation of the corresponding protein to the cytoplasm and most likely represents the best choice due to a greater stability of the corresponding protein [5-8].

Efficient nuclear targeting of scFv fragments has been obtained by adding the nuclear localisation sequence (NLS) (PKKKRKV) of the large T antigen of SV40 either at the $\mathrm{N}$ - or $\mathrm{C}$-terminal of the molecule. In general, C-terminal addition of three NLS tags may be preferable to achieve a more efficient targeting and to avoid the potential risk of the NLS hindering the N-terminal antigen-binding site [19,29].

Table 1

Targeting signals

\begin{tabular}{lll}
\hline & N-terminus & C-terminus \\
\hline Sec & Hydrophobic leader & - \\
ER & Hydrophobic leader & SEKDEL \\
PM & - & TMD (aa 514-562) \\
Cyt & - & - \\
Nuc & - & PKKKRKV \\
Mit & MSVLTPLLLRGL & - \\
& TGSARRLPVPRAK & \\
\hline
\end{tabular}

These signals have been used to target the intracellular antibodies to the secretory compartment (sec), or anchored in the endoplasmic reticulum (ER), to the plasma membrane (PM), the cytoplasm (cyt), the nucleus (nuc) or the mitochondria (mit).

${ }^{\mathrm{a}}$ Transmembrane domain (TMD) of the PDGF receptor.

${ }^{\mathrm{b}}$ Nuclear localisation sequence of the large T antigen of SV40.

${ }^{c} \mathrm{~N}$-terminal presequence of the subunit VIII of human cytochrome oxidase. 
The mitochondrial targeting signals are $\mathrm{N}$-terminal extensions (presequences) present in most of the nuclearencoded mitochondrial proteins. Similarly to the secretory leader sequence, and unlike the NLS, these sequences are removed once the protein is translocated through the mitochondrial membrane. A chimeric protein has been made with the N-terminal presequence of the subunit VIII of human cytochrome oxidase (COX8.21), covering the cleavage junction, fused to the $\mathrm{ScFv}$ fragment. The resulting molecule correctly localises to mitochondria [19].

Besides the specific targeting signals, $\mathrm{scFv}$ expression vectors contain cassettes that encode for strong promoters. A variety of constitutive promoter elements are available from commercial suppliers, such as EF-BOS (elongation factor-1 $\alpha$ ) or CMV (cytomegalovirus). We have found that CMV immediate early enhancer/promoter elements function particularly well in a wide range of human and murine tumor or normal cell lines. In addition, plasmids contain sequences that encode for the resistance to selection antibiotics such as G418 or hygromycin under the control of an independent promoter. All the expression cassettes encode also for a C-terminal tag in-frame with the scFv, allowing its detection. We have used two alternative tags: the myc tag, which can be revealed with mab IgG 9E10 [32], and the green fluorescent protein (GFP). This reporter protein is widely used in studies of gene expression and protein localisation [33,34], especially for live detection purposes, due to its autofluorescence and stable nature. GFP-fused $\mathrm{scFv}$ constructs have proven to keep their functional activity both in vitro [35] and in vivo [36].

\subsection{Methods for the expression and analysis of scFvs}

$\mathrm{ScFv}$ fragments can be expressed in mammalian cells by using transient or stable transfection procedures. Depending on the cell line, it is possible to use different protocols, based on DEAE-dextran for transient transfection of COS-7 cells or on lipids for transient and stable transfection of most adherent cells. The optimal transfection technique is quite cell type specific and needs to be determined empirically for each system. Typically, cell number and DNA-to-lipid ratios are the two parameters to change in order to achieve better transfection efficiency. We have also used electroporation with good success, especially for the transfection of nonadherent cells. Transfection efficiency is monitored using reporter constructs that encode for GFP, which can be easily detected by fluorescence microscopy or flow cytometry. By using Superfect (Qiagen) and Lipofectamine 2000 reagents (LF2000, Invitrogen), we have successfully transfected many cell types, including mouse fibroblasts NIH-3T3, rat pheochromocytoma PC12, human embryonic kidney HEK 293, human adenocarcinoma $\mathrm{HeLa}$, human tumor pancreatic $\mathrm{PaCa}-2$, human melanoma SK-MEL-28, human neuroblastoma SHSY-
5Y, colon adenocarcinoma HT29, normal human fibroblasts MRC5, and human endothelial HUVEC.

Transient transfection of scFv-encoding vectors optimised for intracellular expression leads to a high level of expression that allows the easy detection and analysis of the antibody. Studies on targeting of $\mathrm{scFv}$ fragments to different intracellular compartments showed that the expression levels of the retargeted antibody domains vary. In general, $\mathrm{scFv}$ fragments expressed in the ER are more stable than scFvs expressed in the cytoplasm. This finding most likely reflects that the reducing environment of this compartment with respect to the secretory pathway prevents the intradomain disulfide bridges of the scFvs from forming $[19,20]$. As a consequence of the lower stability, some scFvs tend to aggregate in granular structures. The number, size, and shape of the aggregating species vary for each $\mathrm{scFv}$, regardless of the presence of the intracellular antigen. As it will be shown below also aggregating scFvs can be exploited for phenotypic knock-out experiments.

We routinely characterise the intracellular folding properties of a new $\mathrm{scFv}$ fragment with ad hoc assay. First, we analyse the intracellular distribution of each new myc-tagged scFv fragment in transfected cells by immunofluorescence.

\subsubsection{Immunofluorescence analysis}

1. Depending on transfection protocol and cell type, plate an appropriate number of cells on glass coverslips coated with poly-L-lysine $(0.1 \mathrm{mg} / \mathrm{ml})$ and transfect them.

2. Rinse the cells three times with phosphate-buffered saline (PBS), fix them with $4 \%(w / v)$ paraformaldehyde in PBS for $10 \mathrm{~min}$ at $\mathrm{rt}$, and permeabilise with Tris-Cl $0.1 \mathrm{M}, \mathrm{pH} 7.6 / 0.2 \%$ Triton $\mathrm{X}-100$ for $5 \mathrm{~min}$ at $\mathrm{rt}$.

3. Incubate the cells for $1 \mathrm{~h}$ at $\mathrm{rt}$ with an appropriate dilution of affinity purified mouse anti-myc 9E10. Rinse three times and incubate for $30 \mathrm{~min}$ with fluorescein-isothiocyanate-conjugated (FITC) goat antimouse IgG (Sigma) diluted in PBS-BSA $0.2 \mathrm{mg} / \mathrm{ml}$.

4. Mount coverslips onto slides with mounting medium (Vectashield, Vector) or PBS/glycerol (3/7 v/v) and examine samples by fluorescence microscopy.

We next compare and quantify the expression levels and the solubility of the newly derived scFvs by analysing the soluble and insoluble proteins extracted from transfected cells. Following is described a simple procedure to separate the two fractions and protocols to analyse the scFv molecules in each pool.

\subsubsection{Preparation of the soluble and insoluble proteins}

1. Lyse a $100 \mathrm{~mm}$ tissue culture dish of transfected cells with $300 \mu \mathrm{l}$ ice-cold extraction buffer containing Tris$\mathrm{Cl} 20 \mathrm{mM}, \mathrm{pH} 8, \mathrm{MgCl}_{2} 20 \mathrm{mM}, 0.5 \% \mathrm{NP} 40,0.1 \mathrm{mg} /$ $\mathrm{ml}$ leupeptin, chymostatin, and aprotinin, and $0.1 \mathrm{mM}$ PMSF for $15 \mathrm{~min}$. 
2. Centrifuge cellular extracts for $15 \mathrm{~min}$ at $4{ }^{\circ} \mathrm{C}$ $(15,000 \mathrm{rpm})$ to separate soluble (supernatant) from insoluble proteins (pellet).

\subsubsection{Analysis of soluble scFv fragments}

1. Incubate $20 \mu \mathrm{l}$ protein $\mathrm{A}$-Sepharose in Tris-Cl $25 \mathrm{mM}, \mathrm{pH} 8.6, \mathrm{NaCl} 150 \mathrm{mM}$ (TBS) o/n at $4^{\circ} \mathrm{C}$ (or protein G-Sepharose in TBS, pH 8.0, for $2 \mathrm{~h}$ ) with $2 \mu \mathrm{g}$ of affinity purified mab 9E10.

2. Wash 9E10-protein A-Sepharose three times with TBS, pH 8.0, by centrifugation for $1 \mathrm{~min}$ at $1500 \mathrm{rpm}$. 9E10-Sepharose beads can be used immediately or stored at $4{ }^{\circ} \mathrm{C}$ for $24 \mathrm{~h}$.

3. Incubate $300 \mu 1$ of the soluble pool with $20 \mu 1$ of 9E10-protein A-Sepharose for $2 \mathrm{~h}$ at $4{ }^{\circ} \mathrm{C}$.

4. Wash the Sepharose beads four times with TBS containing $0.1 \% \mathrm{NP} 40$ and once with Tris-Cl $5 \mathrm{mM}, \mathrm{pH}$ 7.6.

5. Add $10 \mu \mathrm{l}$ of $2 \times$ sample buffer (Tris-Cl $125 \mathrm{mM}$, pH 6.8 , SDS $1 \%$, glycerol $5 \%$, DTT $10 \mathrm{mM}$, and bromophenol blue $0.005 \%$ ), boil for $2 \mathrm{~min}$, and centrifuge for $1 \mathrm{~min}(15,000 \mathrm{rpm}, \mathrm{rt})$.

6. Load the supernatant onto a 10\% SDS-polyacrylamide gel and analyse by Western blot following steps 2-6 described below.

\subsubsection{Western blot of the insoluble scFv fragments}

1. Solubilise pellet fractions (insoluble pool) in $2 \times$ SDS sample buffer, boil the samples for $10 \mathrm{~min}$, and run a $10 \%$ SDS-polyacrylamide gel.

2. Transfer the samples from SDS-polyacrylamide gels to a nitrocellulose membrane or PVDF by electrophoretic transfer using Tris-glycine buffer $20 \%$ (v/v) methanol for $2 \mathrm{~h}$ at $100 \mathrm{~V}$ or o/n at $30 \mathrm{~V}$.
3. Saturate non-specific protein-binding sites incubating the membrane in 5\% non-fat dried milk in TBS/ Tween $0.1 \%$ (TBST) for $1-3 \mathrm{~h}$ at room temperature or o/n at $4{ }^{\circ} \mathrm{C}$.

4. Incubate the membrane with a 1:15,000 dilution of mab 9E10 ascitic fluid in TBST containing 2\% of nonfat dried milk for $1 \mathrm{~h}$ at room temperature and rinse the membranes three times with TBST.

5. Incubate the membrane with a 1:5000 dilution of goat anti-mouse horseradish peroxidase (Amersham) in TBST containing $2 \%$ of non-fat dried milk for $30 \mathrm{~min}$ at $\mathrm{rt}$ and rinse the membranes.

6. Visualise the blots by ECL (Enhanced Chemiluminescence) following the manufacturer's instructions.

\subsection{In vivo detection of the antigen-antibody complex}

An absolute requirement for intracellular antibodies is their ability to interact with the endogenous antigen in vivo. Depending on the property of solubility of the $\mathrm{scFv}$ fragment, this interaction can lead to the formation of an aggregated or a soluble antigen-antibody complex. A model for the formation of these complexes and their subsequent intracellular fate is outlined in Fig. 1. This model is based on the concept that, as suggested for many proteins, the aggregation prone state may represent an intermediate state of the folding process in equilibrium with $\mathrm{scFv}$ native structures. Both forms may give rise to a specific antigen-antibody complex. Our recent results suggest that the intermediate folding state is sufficiently native-like to preserve good antigen-binding affinity and specificity $[25,26,28]$. Under normal conditions, partially folded, misfolded, as well as native $\mathrm{scFv}$

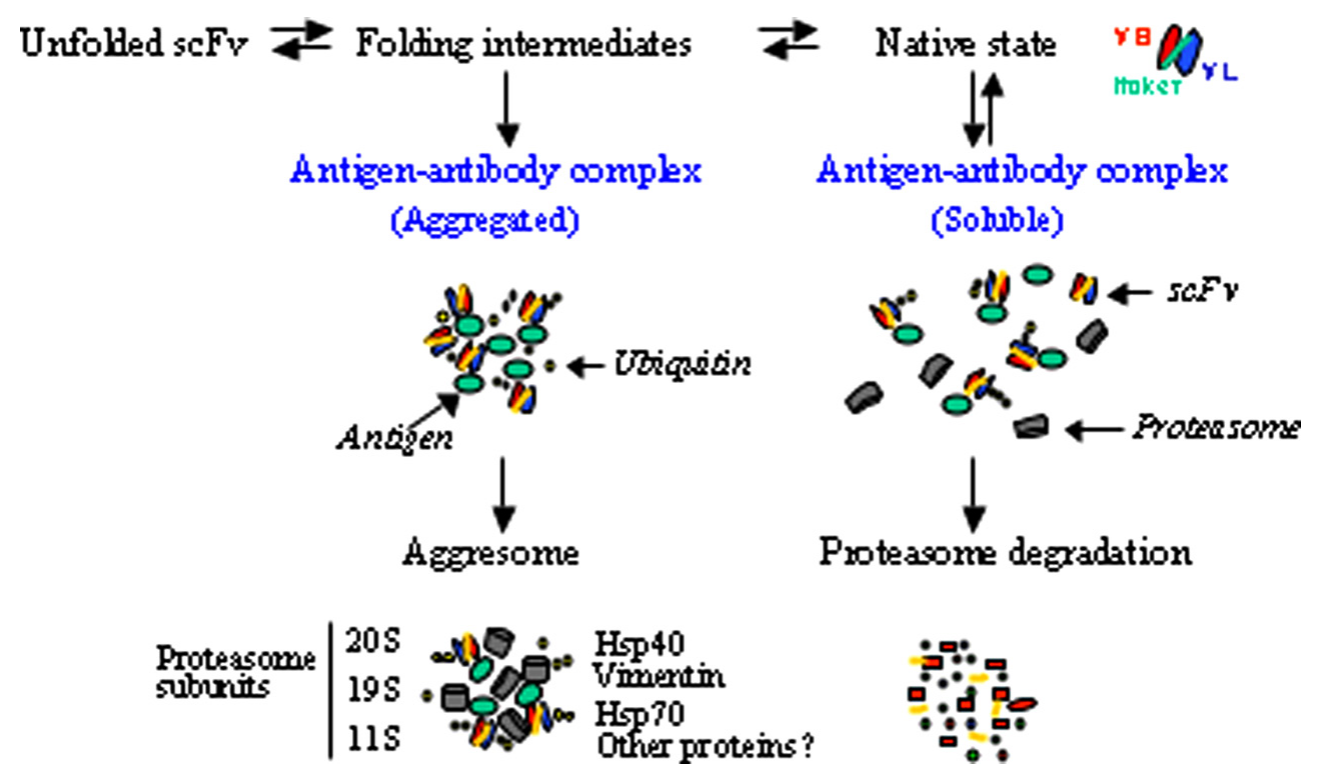

Fig. 1. Proposed mechanism for the formation of the intracellular antigen-antibody complex. Folding intermediates of scFv fragments give rise to aggregated antigen-antibody complexes, which are ubiquitinated, resist proteolysis, and accumulate in vimentin-coated aggresomes containing proteasomal subunits and additional proteins like chaperonins Hsp 40 and Hsp 70. Native scFvs form soluble antigen-antibody complexes that are degraded by the ubiquitin-proteasome system. 
fragments are ubiquitinated and transported to the proteasome system for proteolytic digestion $[37,38]$. However, although the soluble scFvs can be successfully degraded by the ubiquitin-proteasome system, the aggregating species polymerise into insoluble intracellular structures that resist proteolysis. In this case, $\mathrm{scFvs}$ may accumulate in the cytoplasm leading to the formation of pericentriolar, membrane-free, cytoplasmic inclusions named aggresomes, enriched for proteasome subunits, ubiquitin, and molecular chaperones [38,39]. Consistent with this model, targeted inhibition of proteasome increases the formation of large perinuclear $\mathrm{scFv}$-aggresomes and induces the accumulation of multiubiquitinated scFv fragments [36].

The in vivo intracellular interaction between the $\mathrm{scFv}$ and the endogenous antigen can be studied by analysing their intracellular distribution by double immunofluorescence in transfected cells. This allows the in situ monitoring of the efficacy of the interaction before the particular final application envisaged. In the case of aggregating $\mathrm{scFv}$ fragments, the detection of the antigen-antibody complex in aggregates may provide information on the mode of action of that particular intracellular antibody and on the capacity of the $\mathrm{scFv}$ fragment to sequester the antigen in intracellular aggregates.

The above-described protocol for immunofluorescence can be followed until step 3 to reveal the transfected scFv. Then, the antigen can be detected with specific primary and secondary antibodies and analysed by confocal microscope.

Samples can be either examined with a Leica TCS 4D confocal microscopy system equipped with $40 \times 1.00-0.5$ and $100 \times 1.3-0.6$ oil immersion objectives or with a DMRA Leica fluorescence microscope equipped with a DC250 CCD camera. In the first system, images are recorded with simultaneous excitation and detection of both dyes to ensure the alignment to correct for possible crosstalk resulting from dye overlap. Recorded images may be corrected, if necessary, with the MultiColor analysis Package Software by Leica and compared with images recorded with single-dye excitation. The superimposition of the two chromophores in the same image results in a green/red colour scale, leading to yellow colour in the case of co-localisation.

In the second system, a series of optical sections for each fluorophore is acquired and deconvolved using a Leica Qfluoro software. Then, the two chromophores are superimposed in the same image, recorded, and analysed. Deconvolution is a computationally intensive way to process images utilised for removing or reversing blurring present in microscope images due to the limited aperture of the objectives. This technique subtracts blurred light by using complex algorithms, yielding images of comparable resolution to that of confocal microscopy. In this latter case, out-of-focus blur is prevented placing a pinhole aperture between the objective and the detector, through which only in-focus light rays can pass. Thus, while confocal microscopy is specially suited for examining thick specimens such as Xenopus oocytes, embryos or tissues, deconvolution microscopy has proven to be a powerful tool for imaging specimens requiring extremely low light levels, such as living cells bearing GFP protein or fixed culture cells.

Fig. 2 shows two examples of a typical co-localisation experiment viewed with a DMRA Leica fluorescence microscope. We have analysed whether an anti-Ras scFv fragment interacts with p21Ras in the cytoplasm (Fig. 2A') and an anti-chromodomain $\mathrm{scFv}$ interacts with the heterochromatin protein $1 \beta$ in the nucleus (Fig. 2B'). Both experiments show the presence of intracellular aggregates. In the first case, cells are viewed with an anti-p21Ras antibody to visualise the endogenous p21Ras (green signal, panels A and D) and with the antimyc antibody to detect the scFv (red signal, panels B and E). The combination of the two fluorescence patterns is shown in panels $\mathrm{C}$ and $\mathrm{F}$, leading to yellow colour in case of co-localisation. As it can be seen, the anti-Ras $\mathrm{scFv}$ fragment tends to form aggresome-like structures. A strong co-localisation with its specific antigen, p21Ras, is evident in the merged image (yellow colour in panel C). On the contrary, the control anti-NGF scFv fragment is completely aggregated (panel E) but these structures do not contain p21Ras and do not turn yellow (panel F).

In the second case (Fig. 2B'), cells are viewed with an anti-HP1 $\beta$ antibody (green signal, panel A) to visualise the antigen and with the anti-myc antibody (red signal, panel B) to visualise the intracellular anti-chromodomain (CD) scFv. The combination of the two fluorescence patterns is shown in panel $\mathrm{C}$ and the same nucleus is stained also with the blue-fluorescent Hoechst 33258 dye (panel D). As shown, the expression of the anti-CD $\mathrm{scFv}$ in transfected cells results in the formation of distinct nuclear aggregates (panel B), which co-localise with HP1 $\beta$ aggregates (panel $C$ ) and do not coincide with Hoechst-positive heterochromatin blocks (panel D). We conclude that these novel nuclear aggregates consist of HP1 $\beta$ bound to the intracellular scFv.

When expressing soluble scFv fragments in the cytoplasm, the formation of the antigen-antibody complex may be difficult to visualise by immunofluorescence, because the staining is likely to be diffuse. In this case, the direct binding between the $\mathrm{scFv}$ and the antigen can be demonstrated by immunoprecipitation of the $\mathrm{scFv}$ fragment followed by Western blot analysis with specific antibodies directed against the endogenous antigen, namely co-immunoprecipitation. The presence of both molecules in the same blot demonstrates their interaction.

It is worth noting that the co-immunoprecipitation is useless when the $\mathrm{scFv}$ fragment is highly aggregating since no soluble molecules are available to interact with the primary antibody. 

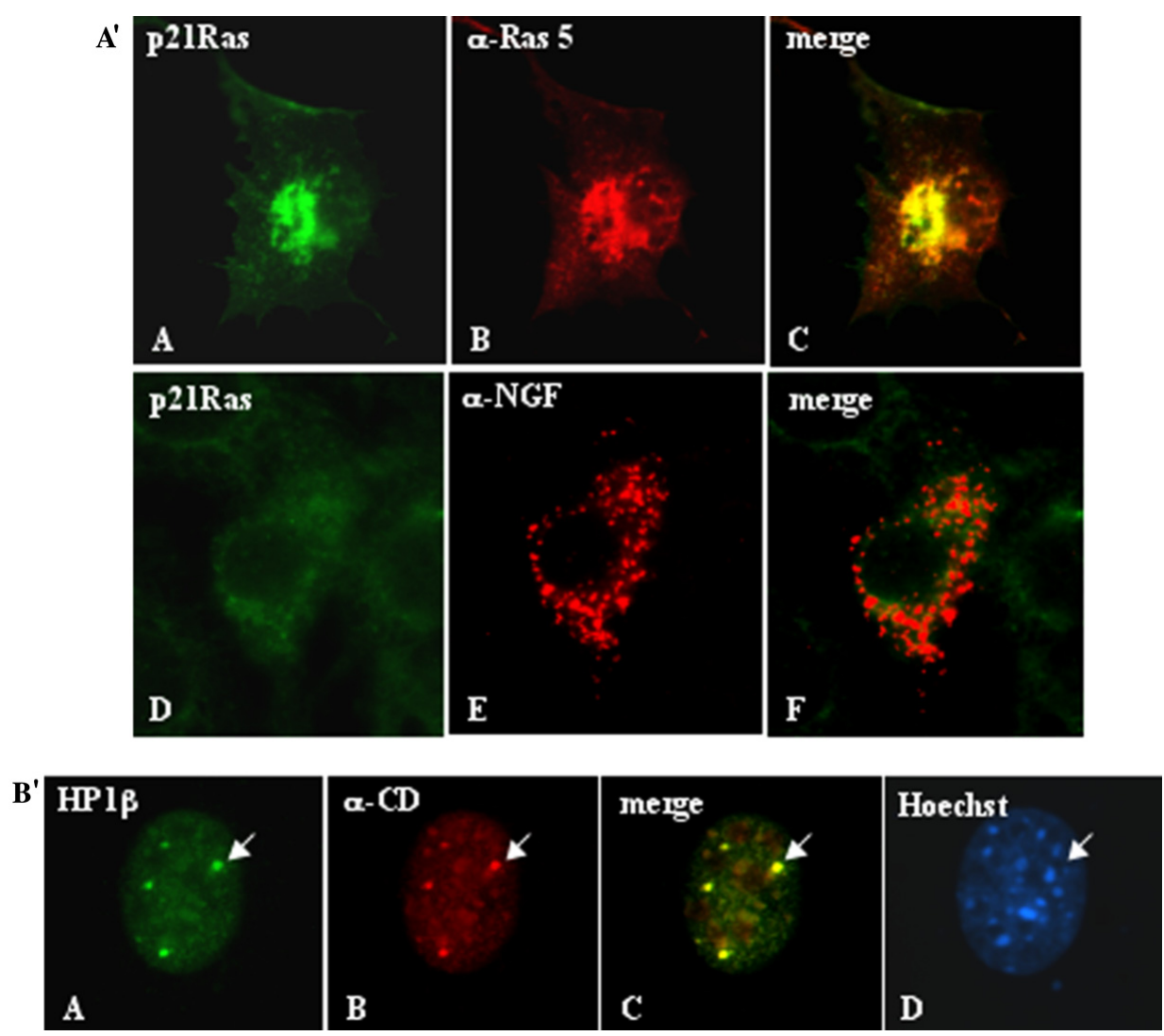

Fig. 2. Co-localisation analysis of scFvs with the endogenous antigen. (A') Double immunofluorescence with anti-p21Ras (A and D) and anti-myc antibodies (B and E) demonstrating the co-localisation of the cytoplasmic scFv fragments and $\mathrm{p} 21 \mathrm{Ras}$ in aggregated structures only in cells expressing the anti-Ras 5 (C) and not in cells expressing the aggregating non-relevant control anti-NGF scFv (F). (B') Co-localisation of anti-chromodomain (CD) scFv with HP1 $\beta$ in nuclear aggregates. (A) The steady state distribution of HP1 $\beta,(B)$ is the same nucleus and depicts the localisation of the anti-CD scFv. (C) Represents the merged image. Arrow points to one of the nuclear aggregates showing co-localisation. In (D) is shown the same nucleus stained with Hoechst 33258, which preferentially stains the heterochromatin blocks. Note that the nuclear aggregates are not coincident with the Hoechst-positive heterochromatic blocks.

\subsection{Functional studies}

\subsubsection{Cell proliferation assay}

In many cases of interest intracellular antibodies are used to interfere with molecules crucially involved in cell proliferation, like p21Ras. Ras is a small GTP-binding protein that plays a critical role in the regulation of cell proliferation, oncogenic transformation, and differentiation [40]. In particular, p21Ras is required for G1-S transition and this activity can be measured by evaluating the entry of cells in the S-phase of the cell cycle. One method of measurement is bromodeoxyuridine (BrdU) incorporation in transfected cells. This procedure consists in pulsing growing cells with $10 \mu \mathrm{M} \mathrm{BrdU}$ for $24 \mathrm{~h}$ and detecting BrdU-positive cells by immunofluorescence analysis using an anti-BrdU monoclonal antibody (Boehringer-Mannheim) containing nucleases for DNA denaturation. BrdU-positive cells are counted from mock and scFv transfected cells [25]. At least 100-150 positively transfected cells should be counted for each experiment. The usage of scFv-GFP-fused chimeras allows a prompt visualisation of transfected cells avoiding the immunofluorescence steps required for $\mathrm{scFv}$ detection [36]. Transfection with a parental vector containing no cDNA insert as well as with a non-relevant $\mathrm{scF} F$ fragment provides important information about the toxicity associated with a particular transfection technique in the specific cell line under investigation and/or possible nonspecific interference with the BrdU assay.

\subsubsection{Cell death assay}

Many proteins may be absolutely required for cell survival, or may induce or prevent apoptosis. Ablation of these proteins by intracellular antibodies may lead to a lethal phenotype, which can be studied by a number of different assays. In particular, we have set up the following protocol to quantify the effect of anti-Ras [41] and anti-chromodomain scFvs [28] on cell death. We have exploited two well-characterised markers of apoptosis. First, Annexin V, which detects the translocation of phosphatidylserine at the level of the plasma membrane. Second, we used the blue fluorescent dye Hoechst 33342, which stains the condensed chromatin of apoptotic cells more brightly than the chromatin of non-apoptotic cells 
in vivo. On the basis of the combined staining patterns of these apoptotic markers, it is possible to distinguish between normal and apoptotic cells.

1. Incubate scFv-GFP transfected cells for $15 \mathrm{~min}$ at $\mathrm{rt}$ with a 1:50 dilution of Annexin V-Alexa 568 reagent (Roche) and an appropriate dilution of Hoechst 33342 (Sigma) in Hepes solution (Roche).

2. Wash the cells by dipping the glass coverslips serially into two beakers containing PBS.

3. Fix and permeabilise the cells with ice-cold acetone/ methanol solution $(7 / 3 \mathrm{v} / \mathrm{v})$ at $-20^{\circ} \mathrm{C}$ for $30 \mathrm{~min}$.

4. Air dried coverslips for $15 \mathrm{~min}$ and wash three times in PBS.

5. Mount coverslips onto slides and examine samples by fluorescence microscopy for detection of Annexin V/ Hoechst 33342 staining. At least 100-150 scFv-GFPpositive cells should be analysed for each experiment.

\subsubsection{Proteasome activity assay}

This assay can be used to evaluate the inhibitory effect of $\mathrm{scFv}$ fragments directed against proteins belonging to the proteasome degradation machinery. Moreover, it can also be applied for evaluating the impact of scFv expression on proteasome function in the case of aggregating antibody domains that have proven to be cytotoxic or apoptotic. It is worth noting that the overexpression of aggregating misfolded proteins is often associated to up-regulation of aggresome formation, altered proteasome distribution, and proteasome dysfunction [39].

We developed a new experimental protocol based on the degradation of an ectopically expressed protein specifically degraded by the ubiquitin-proteasome system (UPS). For this purpose we have used the sec- $\alpha \mathrm{D} 11 \mathrm{scFv}$ fragment, a soluble protein expressed in the secretory compartment [42]. This molecule is ubiquitinated and degraded by the UPS, and its degradation is specifically inhibited by the proteasome inhibitor lactacystin [43]. Therefore, it represents a suitable reporter for proteasome activity, which we call single-chain proteasome substrate (scPs). Accumulation of this reporter protein is a measurement of proteasome dysfunction. The method described below has been optimised for 3T3 K-Ras fibroblasts.

1. Plate $1 \times 10^{6} 3 \mathrm{~T} 3 \mathrm{~K}$-Ras cells on a $100 \mathrm{~mm}$ tissue culture dish for each experimental point.

2. Co-transfect $5 \mu \mathrm{g}$ DNA plasmid encoding for myctagged scPs reporter protein and $5-10 \mu \mathrm{g}$ of GFPtagged scFvs of interest.

3. Harvest the cells $24-48 \mathrm{~h}$ later and collect $1 / 20$ of the original cell suspension for protein determination (Bradford reagent, Bio-Rad).

4. Lyse the cells in $4 \times$ sample buffer for $30 \mathrm{~min}$ on ice.

5. Centrifuge the samples for $5 \mathrm{~min}(13,000 \mathrm{rpm})$ at room temperature and boil for $8 \mathrm{~min}$.

6. Load equal amounts of proteins for each sample and run a $10 \%$ SDS-polyacrylamide gel.

7. Analyse by Western blotting using mouse anti-myc monoclonal antibody 9E10.

8. Strip the same blot and analyse it with anti-HP1 $\beta$ $\mathrm{IgG}$ to verify that the same amount of protein is loaded in each lane and with anti-GFP IgG to monitor GFP-fused $\mathrm{scFv}$ expression.

To quantify the proteasome inhibition, the same test can be done in the presence of serial dilutions of the proteasome inhibitor lactacystin to perform a doseresponse curve. This compound affects metabolic turnover of proteins that are specifically degraded by UPS and, consequently, it induces an accumulation of the scPs reporter band. A direct densitometric comparison of the intensity of the scPs band due to lactacystin treatment can be related to the inhibition induced by any scFv-GFP.

1. Plate $1 \times 10^{6}$ of $3 T 3 \mathrm{~K}-$ Ras cells on a $100 \mathrm{~mm}$ tissue culture dish for each experimental point.

2. Co-transfect $5 \mu \mathrm{g}$ DNA plasmid encoding for myctagged scPs and $5 \mu \mathrm{g}$ of a non-relevant scFv-GFP or carrier DNA.

3. Forty hours later incubate the cells with 1, 3, and $5 \mu \mathrm{M}$ of lactacystin for $8 \mathrm{~h}$ in complete cell growth medium.

\section{Proteasome activity assay}

A

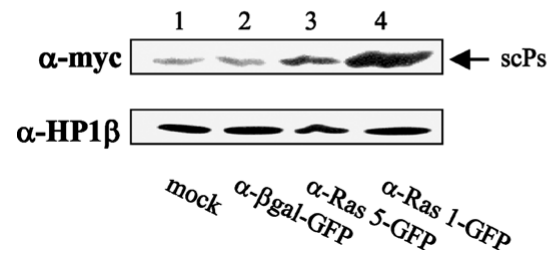

B

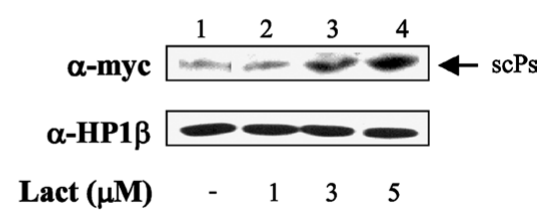

Fig. 3. In vivo proteasome activity assay. (A) Western blot analysis of total cell extract of NIH 3T3 Ki-Ras cells co-transfected with the myc-tagged scPs and different amounts of scFv-GFP DNA plasmids, as indicated. Blots were detected using anti-myc 9E10 and anti-HP1 $13 \mathrm{IgG}$ antibodies. Arrow points to the scPs protein. (B) Western blot analysis of total cell extract of NIH 3T3 Ki-Ras cells co-transfected with the myc-tagged scPs and the non-relevant anti- $\beta \mathrm{Gal}-\mathrm{GFP}$ scFv, incubated or not with different concentrations of lactacystin for $6 \mathrm{~h}$, as indicated. Blots were detected using anti-myc IgG and anti-HP1ßIgG antibodies. Arrow points to the proteasome substrate band. Equal amount of proteins was loaded for each experimental point. 
4. Harvest the cells, determine protein concentration, and perform steps 4-7 of the previous protocol.

In the experiment shown in Fig. 3, the expression of anti-Ras 1 resulted in the inhibition of proteasome activity comparable to that obtained with $5 \mu \mathrm{M}$ lactacystin (see scPs bands in lanes 4 of Figs. 3A and B) and between 1 and $3 \mu \mathrm{M}$ for anti-Ras 5 (see lane 3 in Fig. 3A and lanes 2 and 3 in Fig. 3B). On the other hand, transfection of cells with the cytosolic anti- $\beta \mathrm{Gal}-\mathrm{scFv}$-GFP does not influence the intracellular level of the scPs (Fig. 3A, lane 2). Equal amounts of proteins were loaded in the gel as revealed by anti-HP1 $\beta$ immunoblotting.

\subsection{Concluding remarks}

Recombinant antibodies, in particular $\mathrm{scFv}$ fragments, have been utilised as ectopically expressed genes to confer a phenotype of interest in different biological systems, from plants to mammals.

Since the first reports describing the successful inhibition of a gene product by the intracellular antibody approach 10 years ago, this technology has seen sophisticated improvements and applications. Many open questions concerning the mode of action of intracellular antibodies have been solved, including information on their in vivo folding, the formation of the antigen-antibody complex, and the fate of the complex in any compartment of a mammalian cell.

Development of intrinsically fluorescent reporter systems, which allow rapid localisation and dynamic studies of the target antigens in living cells, and improvements on the in vivo genetic-based selection of scFv fragments suitable for intracellular expression in mammalian cells will better enhance the potential of this approach.

\section{References}

[1] S. Biocca, M.S. Neuberger, A. Cattaneo, EMBO J. 9 (1990) 101-108.

[2] S. Biocca, A. Cattaneo, Trends Cell Biol. 5 (1995) 248-252.

[3] J.H. Richardson, W.A. Marasco, Trends Biotechnol. 13 (1995) 306-310.

[4] A. Cattaneo, S. Biocca, Intracellular antibodies: development and application, Springer Verlag, Berlin, Germany, 1997, pp. 1-196.

[5] S. Biocca, P. Pierandrei-Amaldi, A. Cattaneo, Biochem. Biophys. Res. Commun. 197 (1993) 422-427.

[6] S. Biocca, P. Pierandrei-Amaldi, N. Campioni, A. Cattaneo, Bio/ Technology 12 (1994) 396-399.

[7] L. Duan, O. Bagasra, M.A. Laughlin, J.W. Oakes, R.J. Pomerantz, Proc. Natl. Acad. Sci. USA 91 (1994) 5075-5079.

[8] A.M. Mhashilkar, J. Bagley, S.J. Chen, A.M. Szilvay, D.G. Helland, W.A. Marasco, EMBO J. 14 (1995) 1542-1551.

[9] W.A. Marasco, W.A. Haseltine, S.Y. Chen, Proc. Natl. Acad. Sci. USA 90 (1993) 7889-7893.

[10] I.J. Rondon, W.A. Marasco, Annu. Rev. Microbiol. 51 (1997) $257-$ 283.
[11] P. Tavladoraki, E. Benvenuto, S. Trinca, D. De Martinis, A. Cattaneo, P. Galeffi, Nature 366 (1993) 469-472.

[12] M. Visintin, E. Tse, H. Axelson, T.H. Rabbitts, A. Cattaneo, Proc. Natl. Acad. Sci. USA 96 (1999) 11723-11728.

[13] P.A. Cohen, J.C. Mani, D.P. Lane, Oncogene 17 (1998) 2445-2456.

[14] D. Jean, C. Tellez, S. Huang, D.W. Davis, C.J. Bruns, D.J. McConkey, S.H. Hinrichs, M. Bar-Eli, Oncogene 19 (2000) 2721-2730.

[15] Caron de Fromentel, N. Gruel, C. Venot, L. Debussche, E. Conseiller, C. Dureuil, J.L. Teillaud, B. Tocque, L. Bracco, Oncogene 18 (1999) 551-557.

[16] A. Khoshnan, J. Ko, P.H. Patterson, Proc. Natl. Acad. Sci. USA 99 (2002) 1002-1007.

[17] D. Graus-Porta, R.R. Beerli, N.E. Hynes, Mol. Cell. Biol. 15 (1995) 1182-1191.

[18] J. Deshane, F. Loechel, R.M. Conry, G.P. Siegal, C.R. King, D.T Curiel, Gene Ther. 1 (1994) 332-337.

[19] S. Biocca, F. Ruberti, M. Tafani, P. Pierandrei-Amaldi, A. Cattaneo, Bio/Technology 13 (1995) 1110-1115.

[20] A. Cattaneo, S. Biocca, Trends Biotechnol. 17 (1999) 115-121.

[21] S. Jung, A. Honegger, A. Pluckthun, J. Mol. Biol. 294 (1999) 163-180.

[22] M. Visintin, G. Settanni, A. Maritan, S. Graziosi, J.D. Marks, A. Cattaneo, J. Mol. Biol. 317 (2002) 73-83.

[23] E. Tse, M.N. Lobato, A. Forster, T. Tanaka, T.Y.G. Chumg, T.H Rabbits, J. Mol. Biol. 317 (2002) 85-94.

[24] A.A. der Maur, C. Zahnd, F. Fischer, S. Spinelli, A. Honegger, C. Cambillau, D. Escher, A. Pluckthun, A. Barberis, J. Biol. Chem. 277 (2002) 45075-45085.

[25] A. Cardinale, M. Lener, S. Messina, A. Cattaneo, S. Biocca, FEBS Lett. 439 (1998) 197-202.

[26] M. Lener, I.R. Horn, A. Cardinale, S. Messina, U.B. Nielsen, S.M. Rybak, H.R. Hoogenboom, A. Cattaneo, S. Biocca, Eur. J. Biochem. 267 (2000) 1196-1205.

[27] K.S. Yi, J.H. Chung, Y.H. Lee, H.G. Chung, I.J. Kim, B.C. Suh, E Kim, L. Cocco, S.H. Ryu, P. Suh, Oncogene 20 (2001) 7954-7964.

[28] I. Filesi, A. Cardinale, S. Van der Sar, I.G. Cowell, P.B. Singh, S. Biocca, J. Cell Sci. 115 (2002) 1803-1813.

[29] L. Persic, M. Righi, A. Roberts, H.R. Hoogenboom, A. Cattaneo, A. Bradbury, Gene 187 (1997) 1-8.

[30] Z. Eshar, T. Waks, G. Gross, D.G. Schindler, Proc. Natl. Acad. Sci. USA 90 (1993) 720-724.

[31] J.D. Chesnut, A.R. Baytan, M. Russel, et al., J. Immunol. Methods 193 (1996) 17-27.

[32] G.I. Evan, G.K. Lewis, G. Ramsay, J.M. Bishop, Mol. Cell. Biol. 5 (1985) 3610-3616.

[33] M. Chalfie, G. Euskirchen, W.W. Ward, D.C. Prasher, Science 263 (1994) 802-805.

[34] A.B. Cubbitt, R. Heim, S.R. Adams, A.E. Boyd, L.A. Gross, R.Y. Tsien, Trends Biochem. Sci. 20 (1995) 448-455.

[35] M.A. Hink, R.A. Griep, J.W. Borst, A. van Hoek, M.H. Eppink, A Schots, A.J. Visser, J. Biol. Chem. 275 (2000) 17556-17560.

[36] A. Cardinale, I. Filesi, S. Biocca, Eur. J. Biochem. 268 (2001) 268-277.

[37] A. Ciechanover, A. Orian, L.A. Schwartz, Bioessay 22 (2000) 442 451.

[38] J.A. Johnston, C.L. Ward, R.R. Kopito, J. Cell Biol. 143 (1998) 1883-1898.

[39] R.R. Kopito, R. Sitia, EMBO Rep. 1 (2000) 225-231.

[40] S.L. Campbell, R. Khosravi-Far, K.L. Rossman, G.J. Clark, C.J. Der, Oncogene 17 (1998) 1395-1413.

[41] A. Cardinale, I. Filesi, S. Mattei, S. Biocca, Eur. J. Biochem. 270 (2003) 3389-3397.

[42] F. Ruberti, A. Bradbury, A. Cattaneo, Cell. Mol. Neurobiol. 13 (1993) 559-568.

[43] G. Fenteany, S.L. Schreiber, J. Biol. Chem. 273 (1998) 8545-8548. 